\title{
Adapting the Sudden Landslide Identification Product (SLIP) and Detecting Real-Time Increased Precipitation (DRIP) algorithms to map and predict rainfall-triggered landslides in the West-Cameroons' highlands (Central-Africa)
}

\section{CURRENT STATUS: UNDER REVIEW}

Geoenvironmental Disasters $\underline{\underline{2} \text { Springer }}$

ALFRED HOMERE NGANDAM MFONDOUM

Universite de Yaounde I

\ngandamh@yahoo.comCorresponding Author

ORCiD: https://orcid.org/0000-0001-5917-1275

Pauline Wokwenmendam Nguet

Institute of Mining and Geological Research

Jean Valery Mefire Mfondoum

Universite Toulouse 1 Capitole Toulouse School of Economics

Mesmin Tchindjang

Universite de Yaounde I

Sofia Hakdaoui

Universite Mohammed V de Rabat Faculte des Sciences

Ryan Cooper

University of Texas at Dallas Erik Jonsson School of Engineering and Computer Science

Paul Gérard Gbetkom

Aix-Marseille Universite - Campus Aix-en-Provence Schuman

Joseph Penaye

Institute of Mining and Geological Research

Ateba Bekoa

Institute of Mining and geological Research

Cyriel Moudioh

Institute of Mining and Geological Research 
DOI:

10.21203/rs.3.rs-19292/v1

\section{SUBJECT AREAS}

Geology Ecological Modeling

KEYWORDS

SLIP, DRIP, Landsat 8, geohazard, West-Cameroons' Highlands, rainfall-triggered Landslides, $L H Z$, prediction model 
Abstract

Background - The SLIP and DRIP algorithms recently developed correlate Landsat 8 images and local daily precipitation records to map and time rainfall-triggered landslides. In many areas recently affected by that geohazard in west-Cameroon's highlands, only the dry season images are available, while rainfall data are recorded on a monthly scale. Methods - The SLIP algorithm is modified, integrating the inverse NDVI to assess the soil exposure, the Modified Normalized Multi-band Drought Index (MNMDI) combined with the hydrothermal index to assess soil moisture, and the slopes in degrees. They are converted into binned layers and overlaid to map the recent landslide. The DRIP algorithm is also modified, using the monthly rainfall rescaled to a daily window and the days of rainfall per month. Their probability density function (PDF) curves are superimposed and their intersection are used to propose set dichotomous variables before and after the 28 October 2019 landslide event, for a prediction model. Results - The Landslide Hazard Zonation (LHZ) map of latest landslides is effective at $100 \%$, while the overall accuracy is $77.8 \%$ when integrating the control point around the disaster area. Moreover, for 1948-2018 individual thresholds of , and 2019 threshold of between June and October, the risk of rainfall-triggered landslide is 95\%, while the 'no-landslide' probabilities are between $98.95 \%$ and $99.99 \%$. Conclusions - Based on the SLIP and DRIP algorithms, the proposed methodology offers a new alternative in case of voids and gaps between data. Improvements and comparisons with others models are in perspective. Keywords - SLIP, DRIP, Landsat 8, geohazard, West-Cameroons' Highlands, rainfall-triggered Landslides, LHZ, prediction model.

\section{Full Text}

Due to technical limitations, full-text HTML conversion of this manuscript could not be completed. However, the manuscript can be downloaded and accessed as a PDF.

Figures 


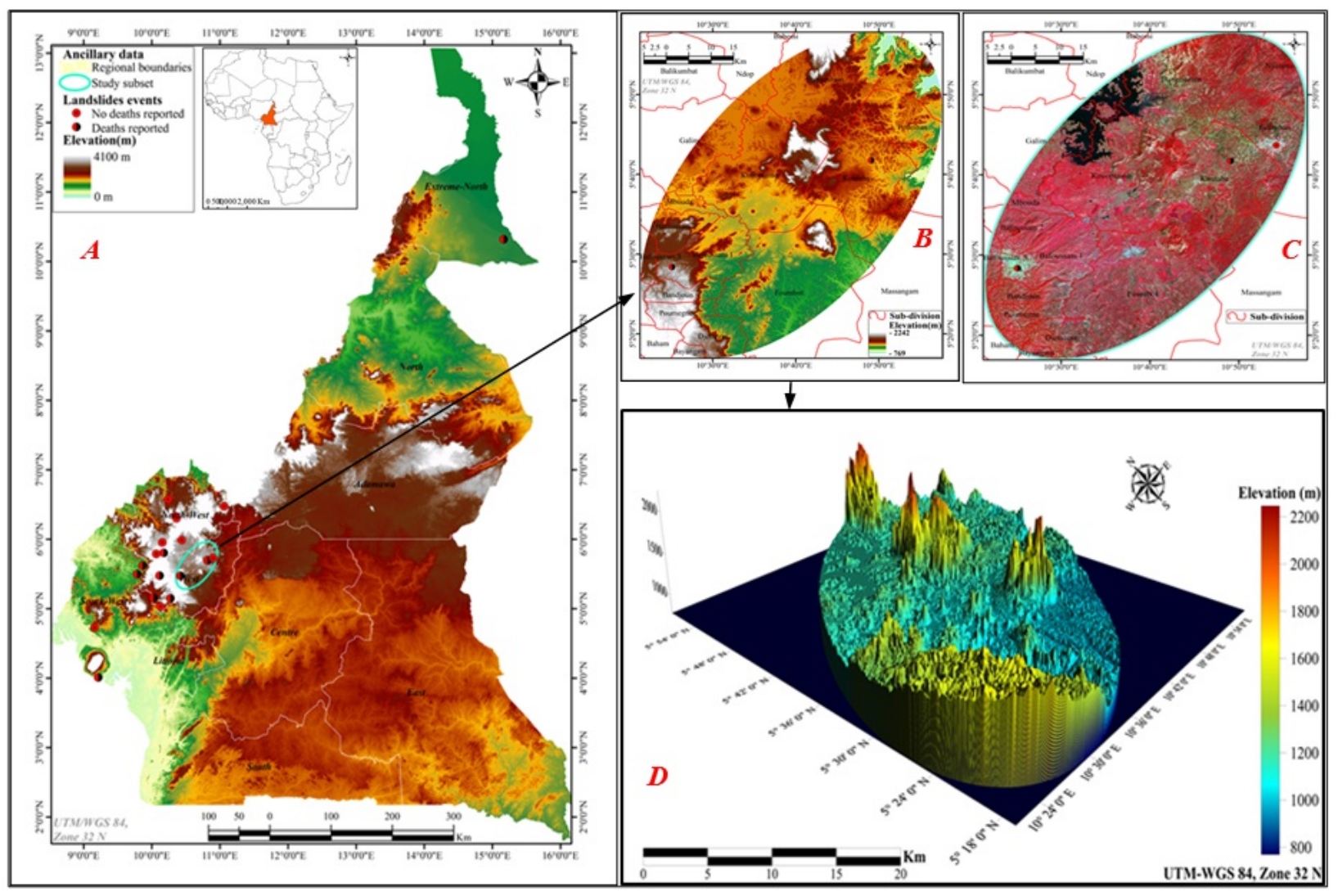

Figure 1

A) Country elevation and landslides events. B) \& C) - Subset of study elevation and Landsat OLI-TIRS image. D) 3-dimensional appraisal of the subset elevation. 


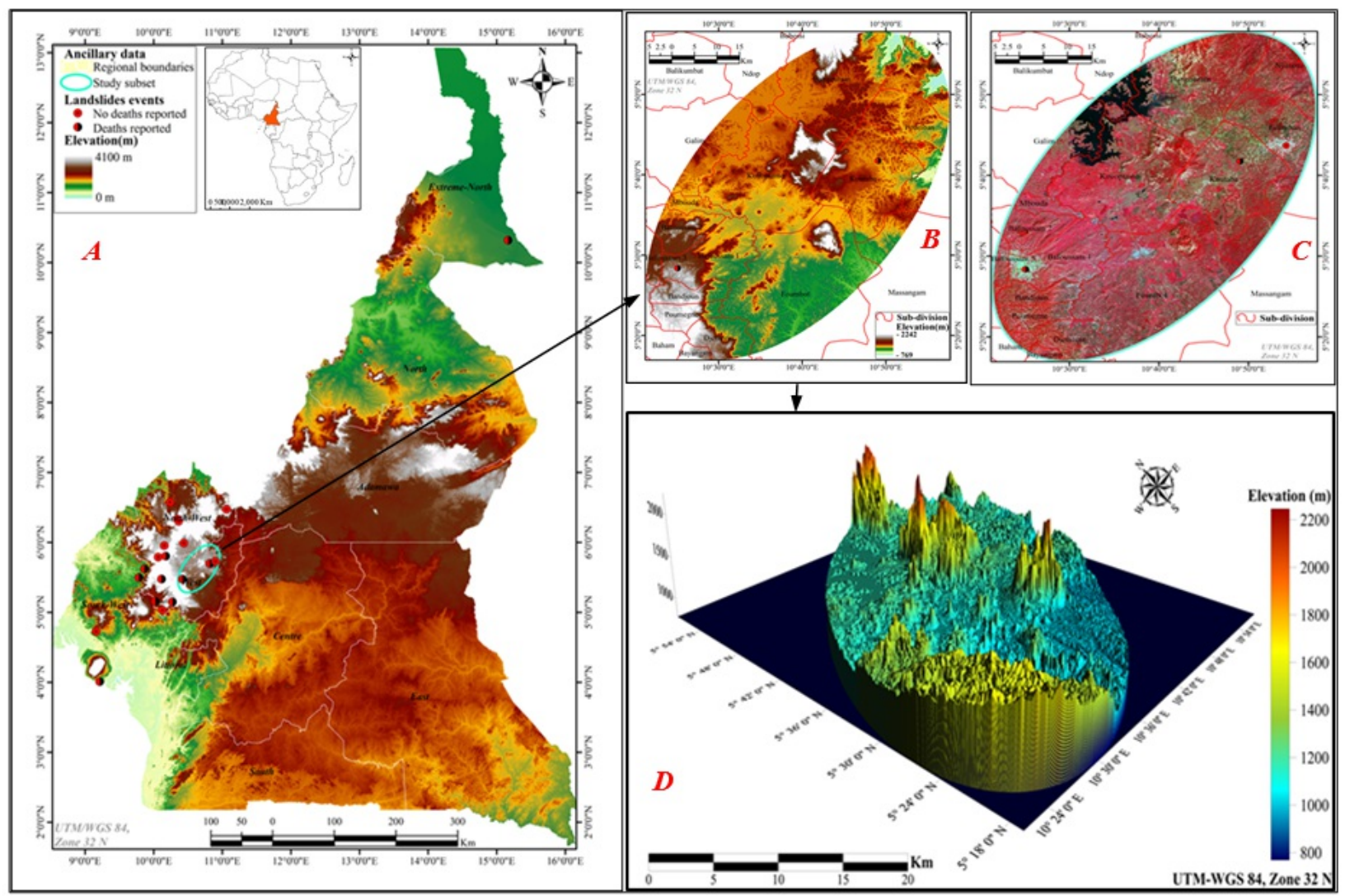

Figure 1

A) Country elevation and landslides events. B) \& C) - Subset of study elevation and Landsat OLI-TIRS image. D) 3-dimensional appraisal of the subset elevation.
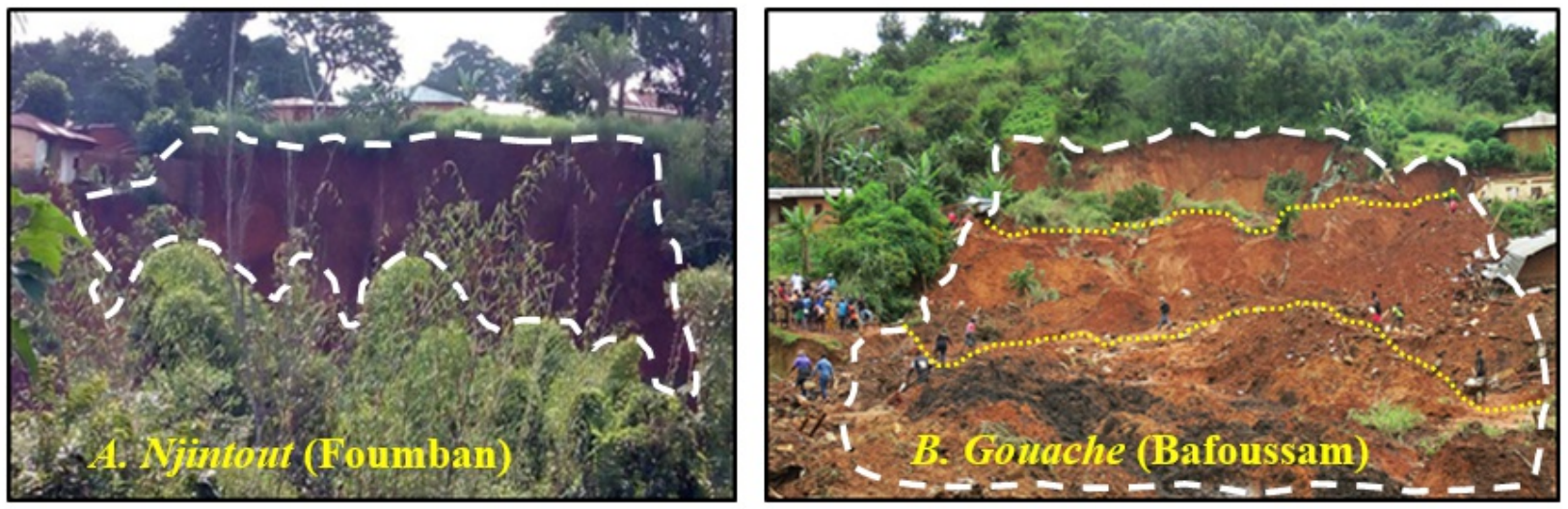

Figure 2

Scarps leaved by the landslides of Foumban (2018-A) and Bafoussam (2019-B). Both events were sudden with transitional to rotational movements, but the one in Foumban happened in one-step, while the one in Bafoussam happened during at least two steps (yellow dashed), justifying three main blocks/stairs. 

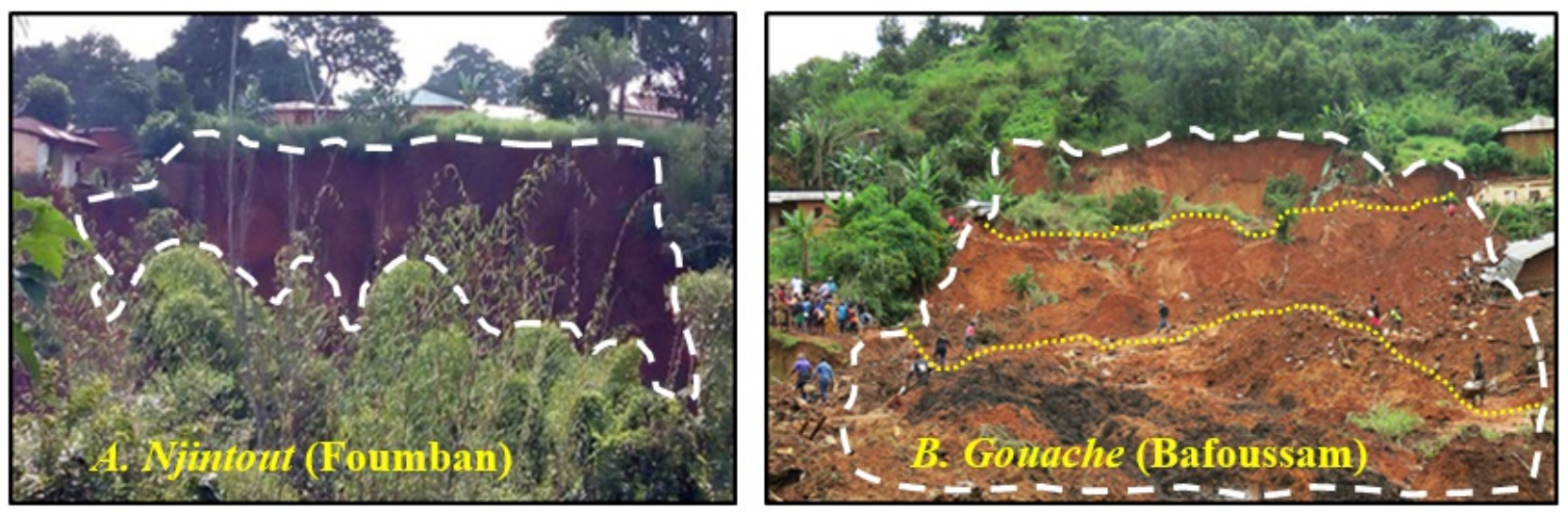

Figure 2

Scarps leaved by the landslides of Foumban (2018-A) and Bafoussam (2019-B). Both events were sudden with transitional to rotational movements, but the one in Foumban happened in one-step, while the one in Bafoussam happened during at least two steps (yellow dashed), justifying three main blocks/stairs.

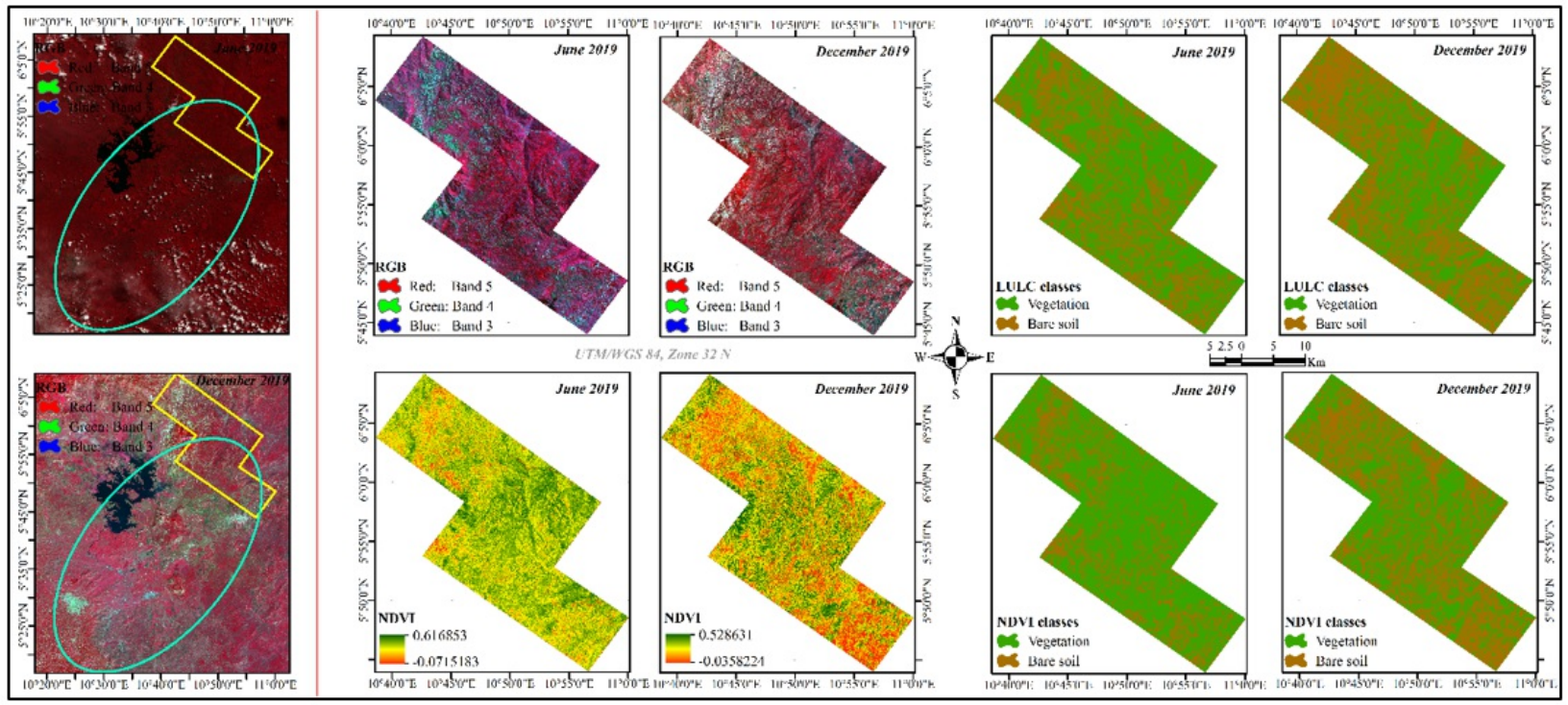

Figure 3

Subset of Landsat 8 images used for Land cover extent approximation 


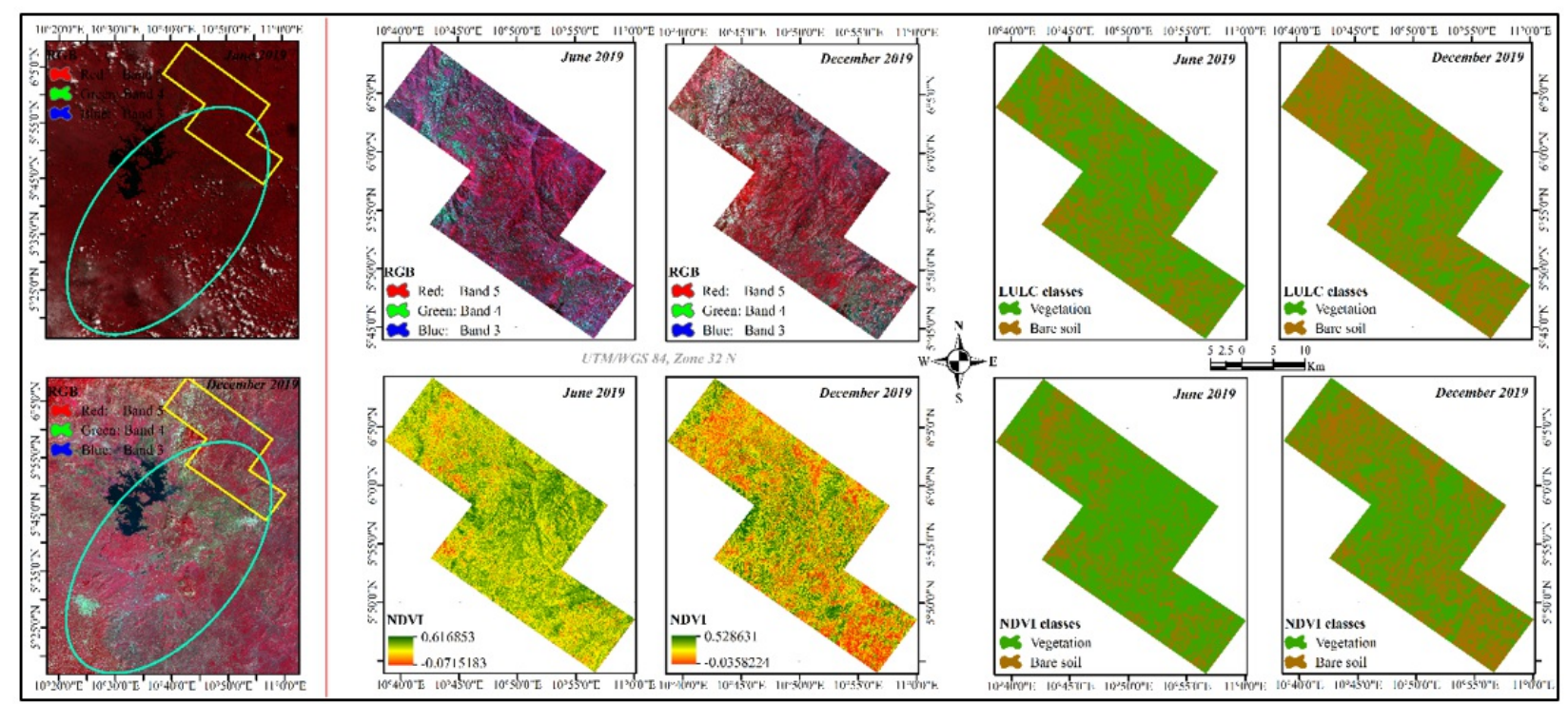

Figure 3

Subset of Landsat 8 images used for Land cover extent approximation

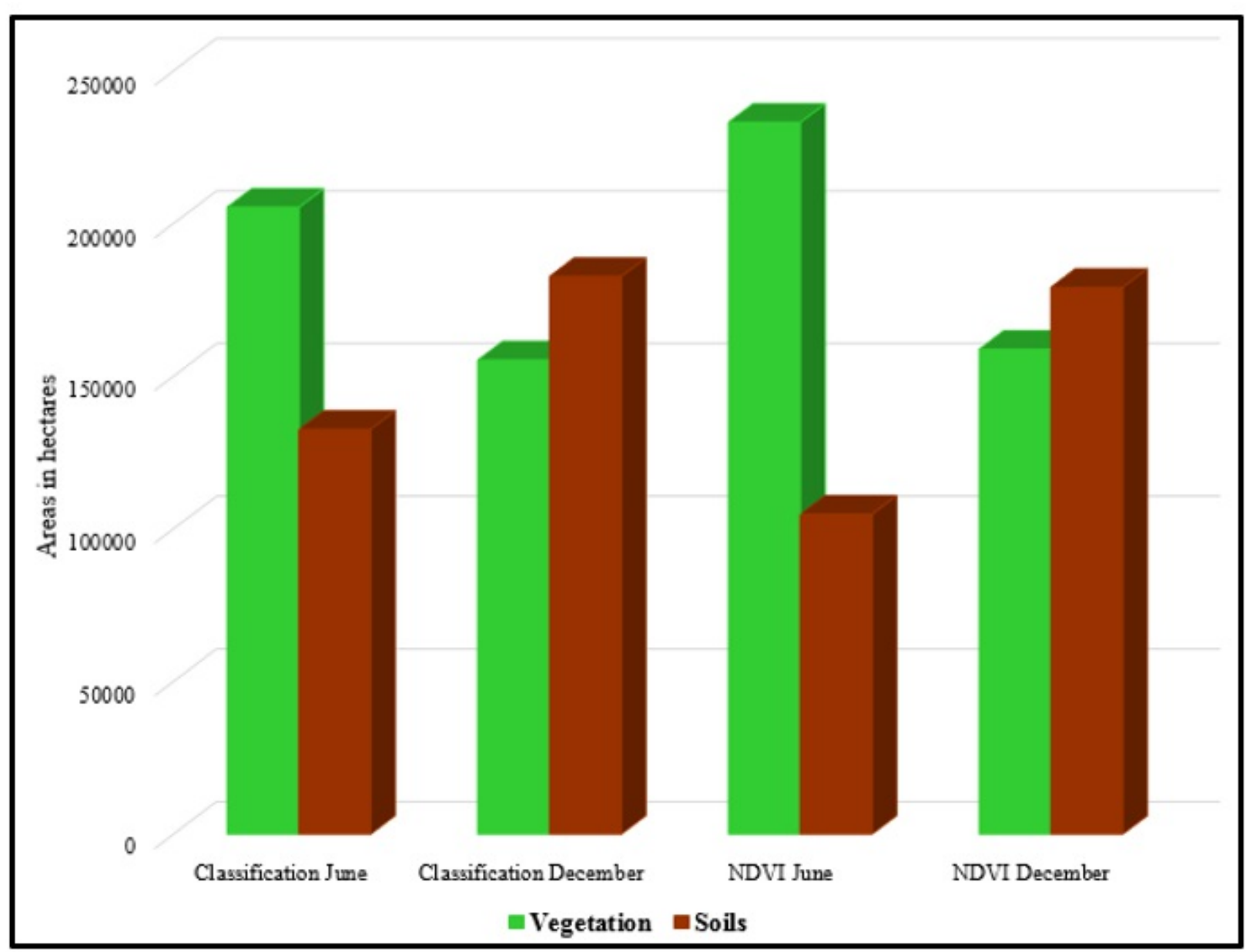

Figure 4

Land Use Land Cover (LULC) - comparison for the classification and the NDVI 


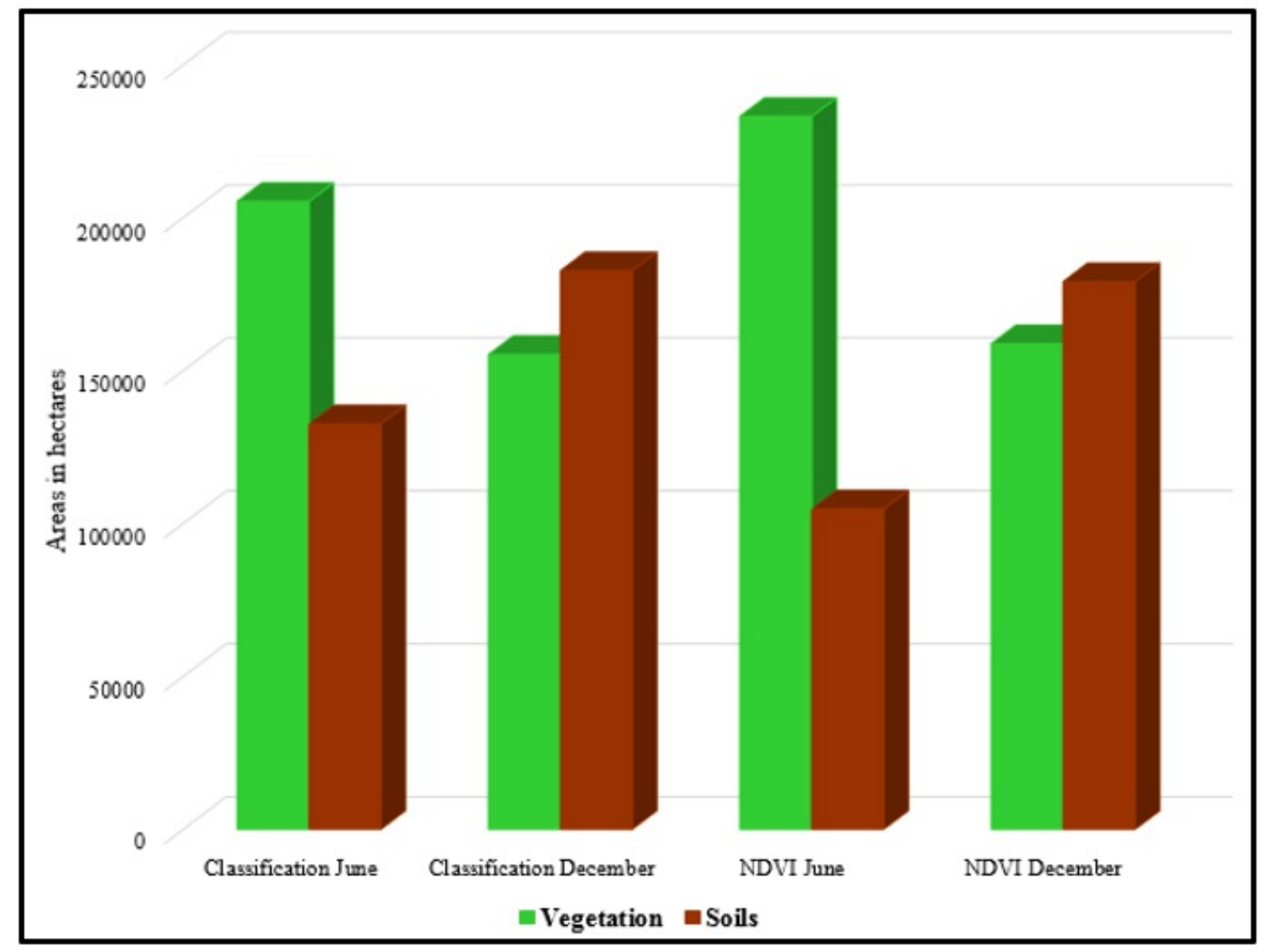

Figure 4

Land Use Land Cover (LULC) - comparison for the classification and the NDVI 


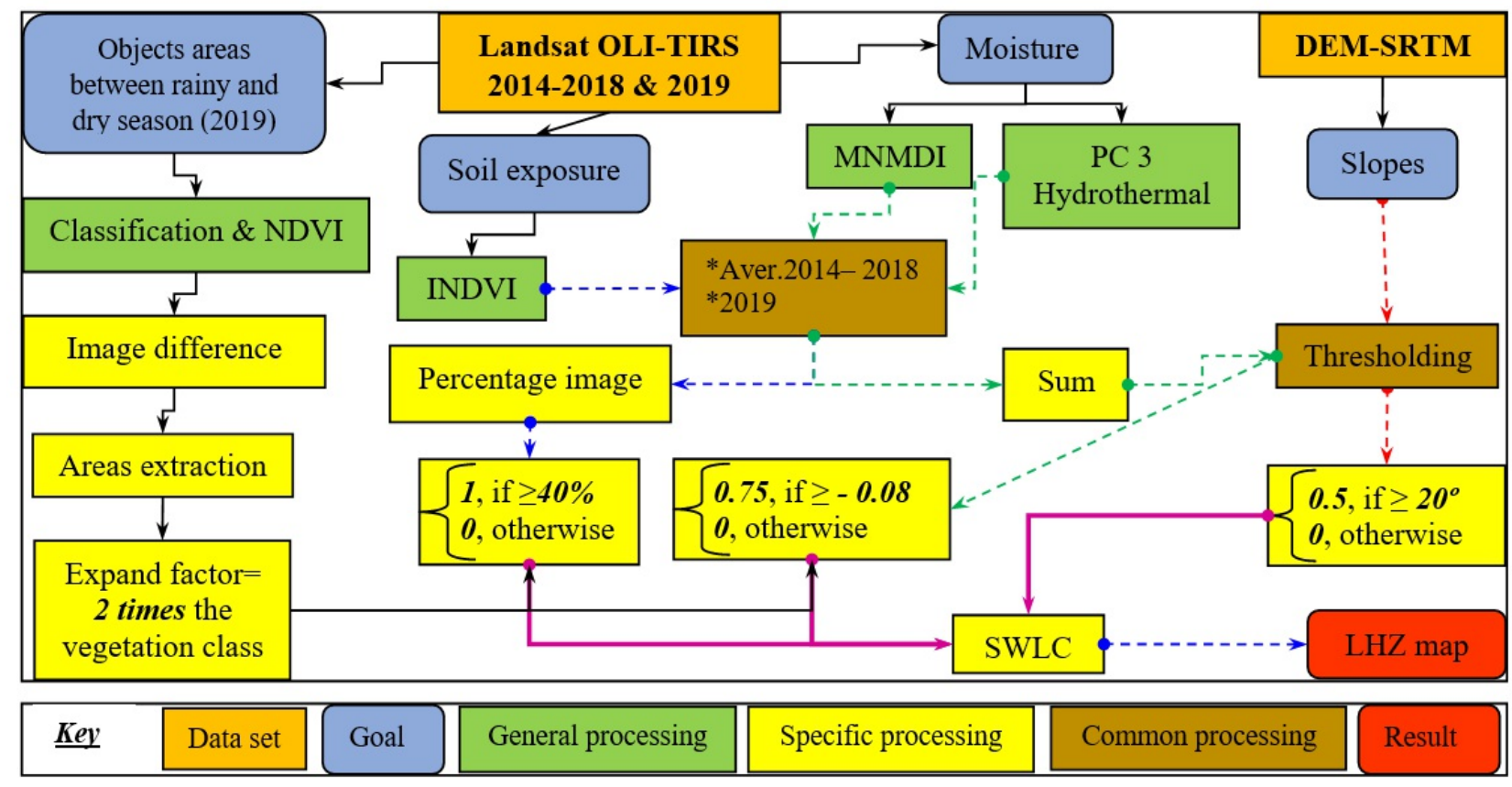

Figure 5

Workflow of the SLIP process

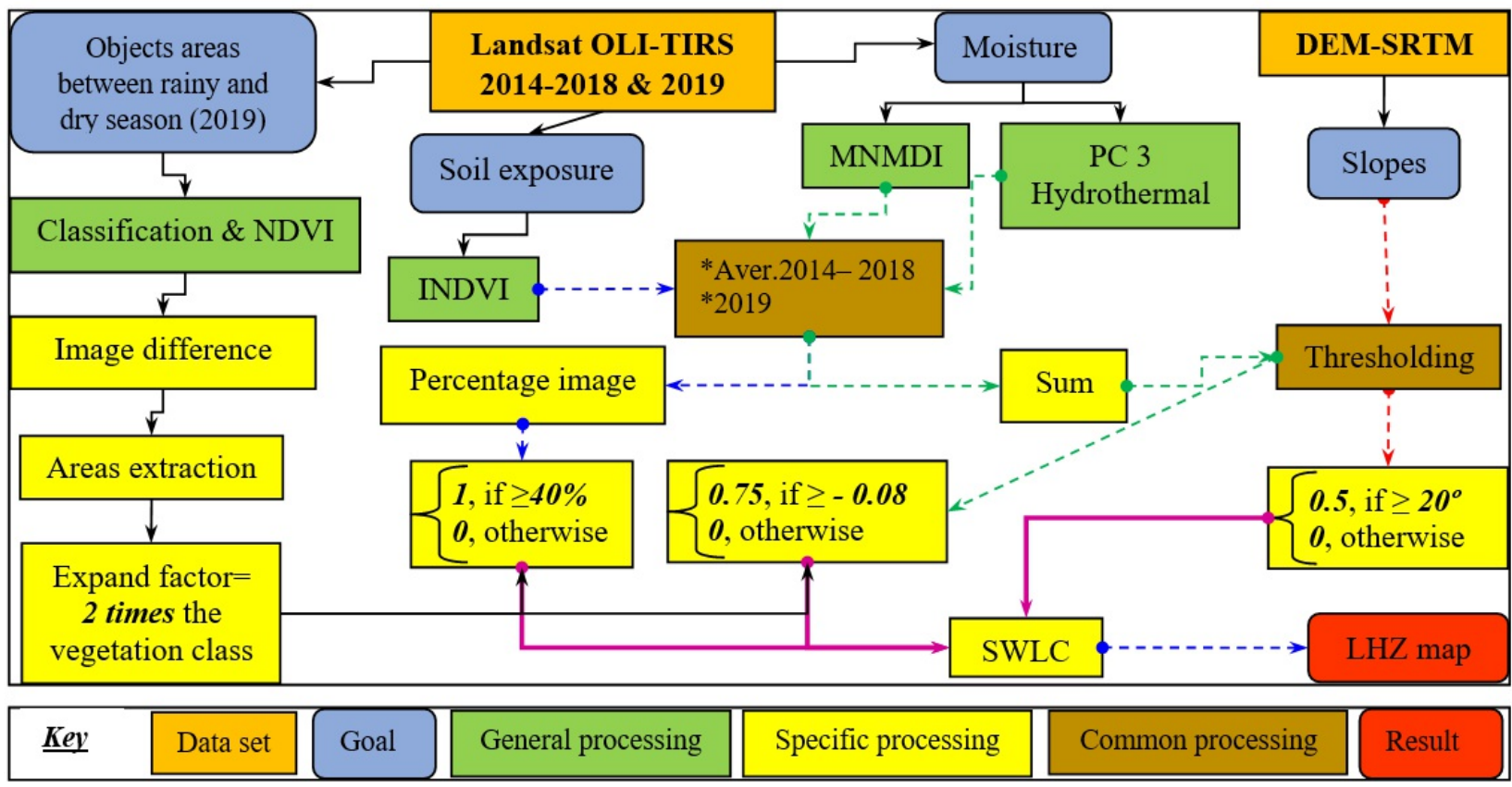

Figure 5

Workflow of the SLIP process 


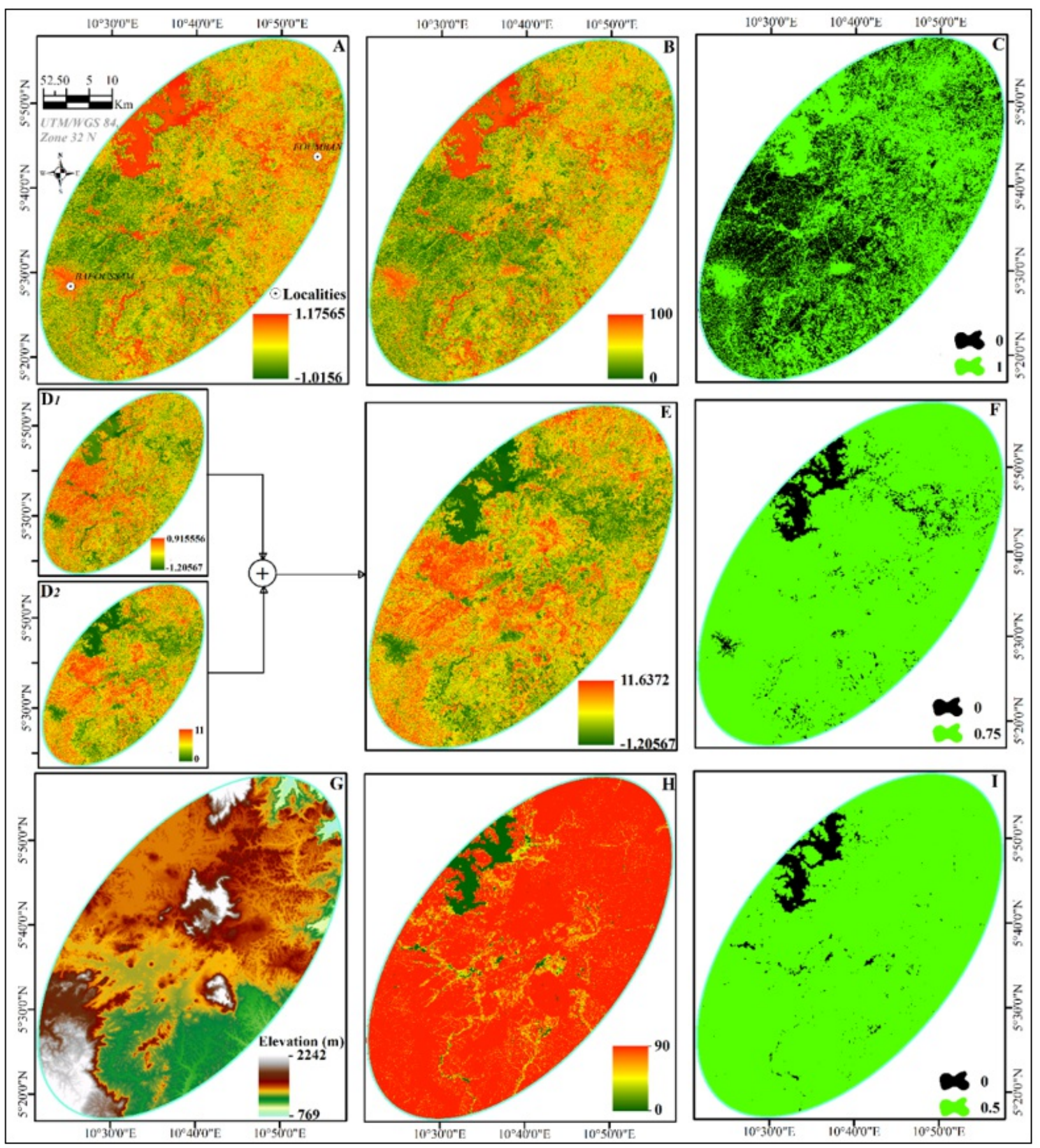

Figure 6

SLIP stretched and conditioned layers. A) INDVI stretched values; B) Barren land binned map; C) MNMDI + hydrothermal stretched map; D) Land moisture binned map; E-Slopes in degrees; F-Slopes binned map. Only remains the triggering factor identified as a long and huge rainfall condition. The DRIP algorithm helps assessing it. 


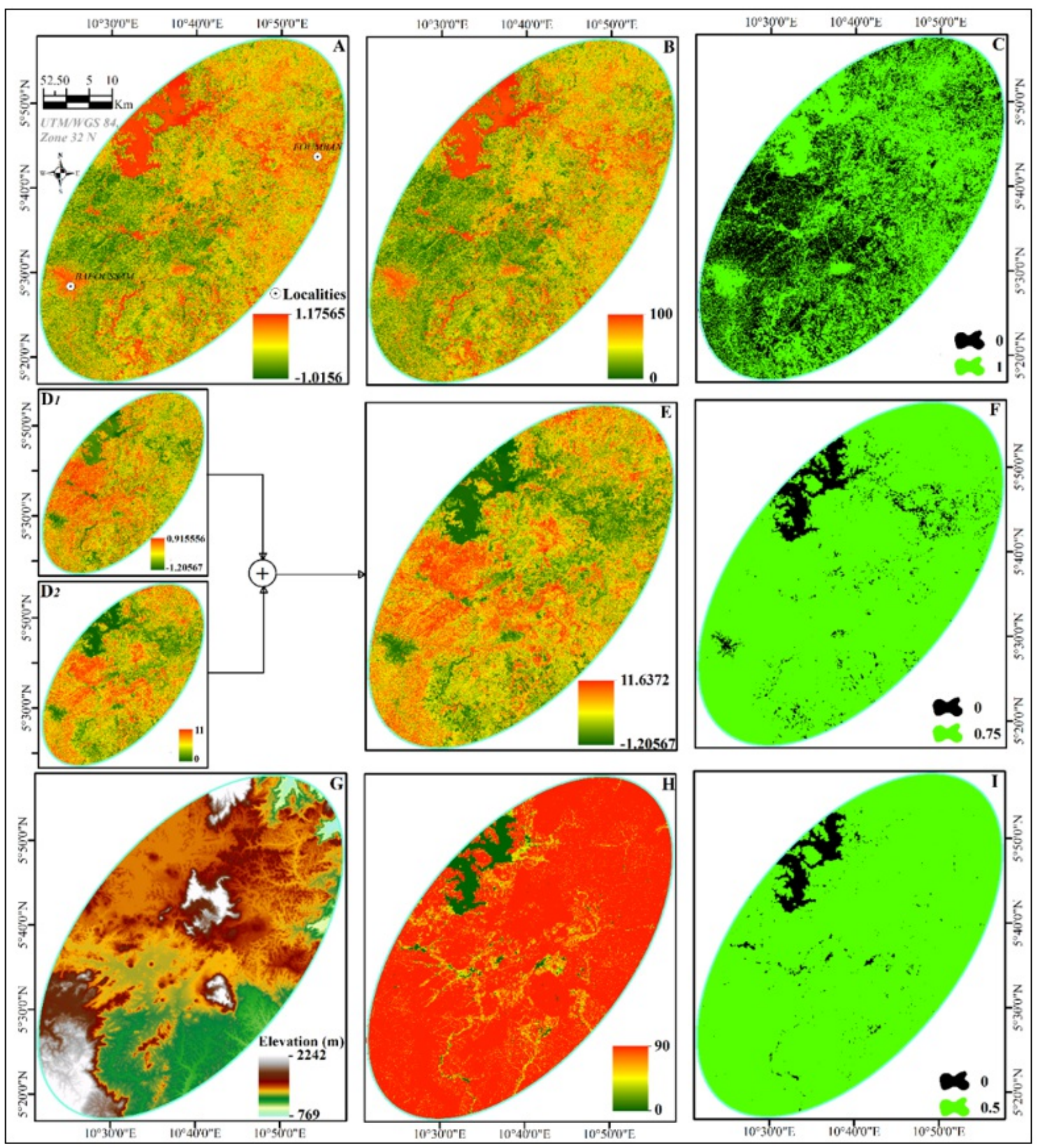

Figure 6

SLIP stretched and conditioned layers. A) INDVI stretched values; B) Barren land binned map; C) MNMDI + hydrothermal stretched map; D) Land moisture binned map; E-Slopes in degrees; F-Slopes binned map. Only remains the triggering factor identified as a long and huge rainfall condition. The DRIP algorithm helps assessing it. 


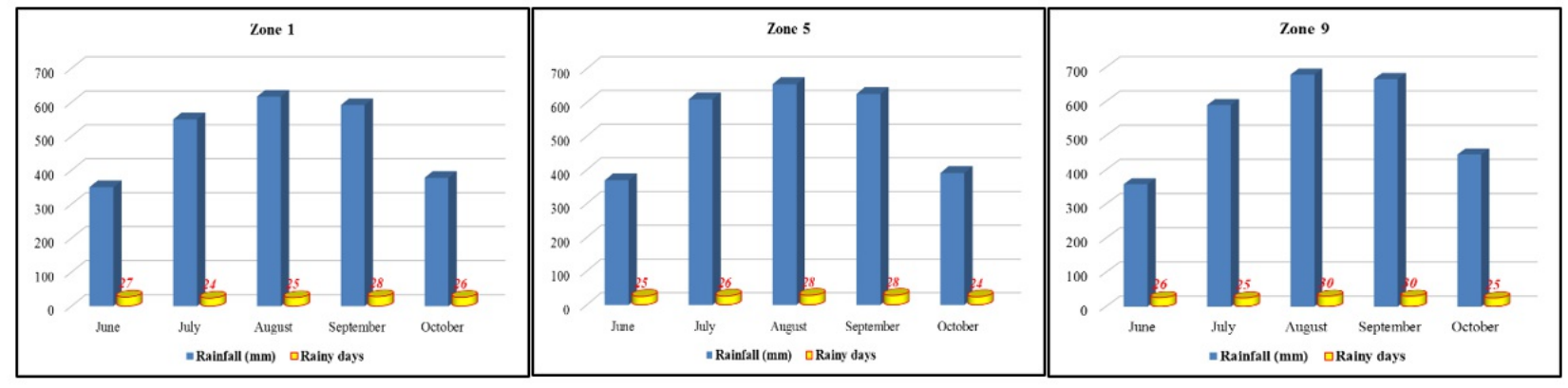

Figure 7

Monthly rainfall and rainy days sampled for three zones of the study area in 2019

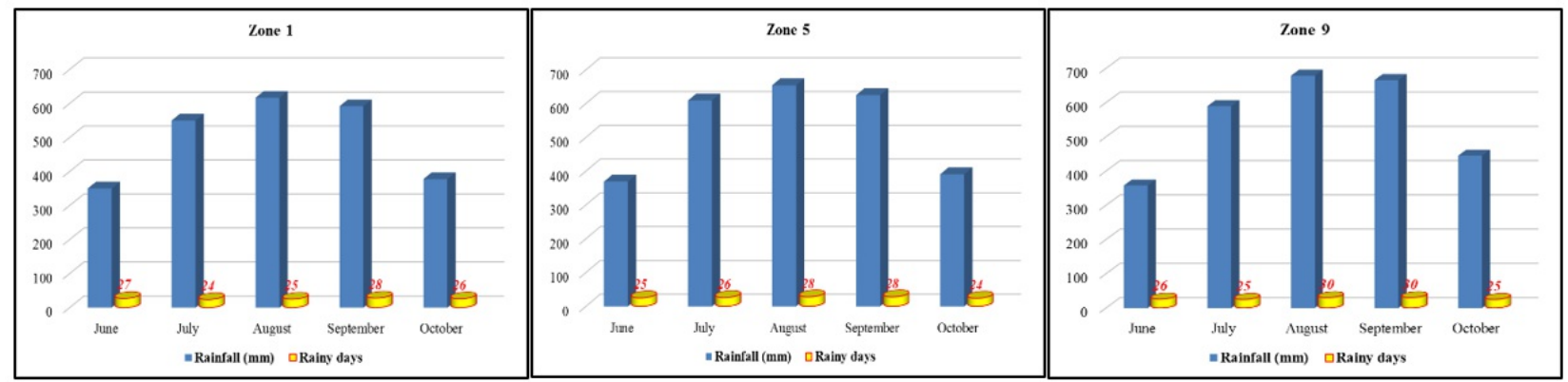

Figure 7

Monthly rainfall and rainy days sampled for three zones of the study area in 2019
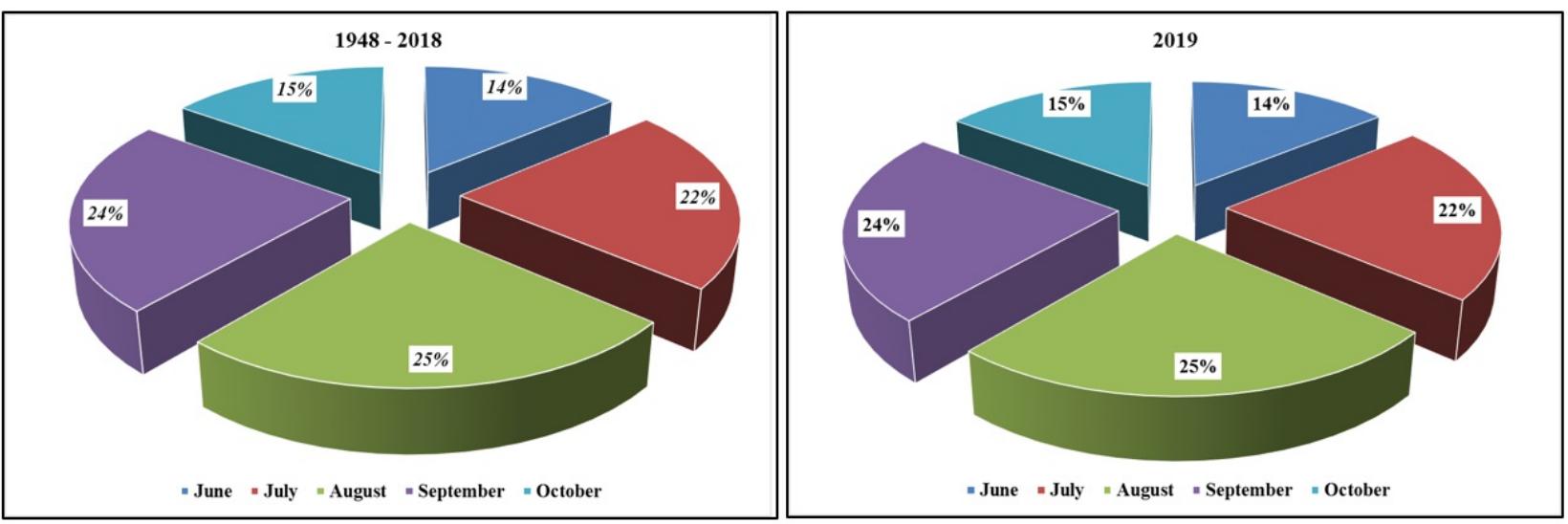

Figure 8

Percentages of monthly rainfall For June-October period 

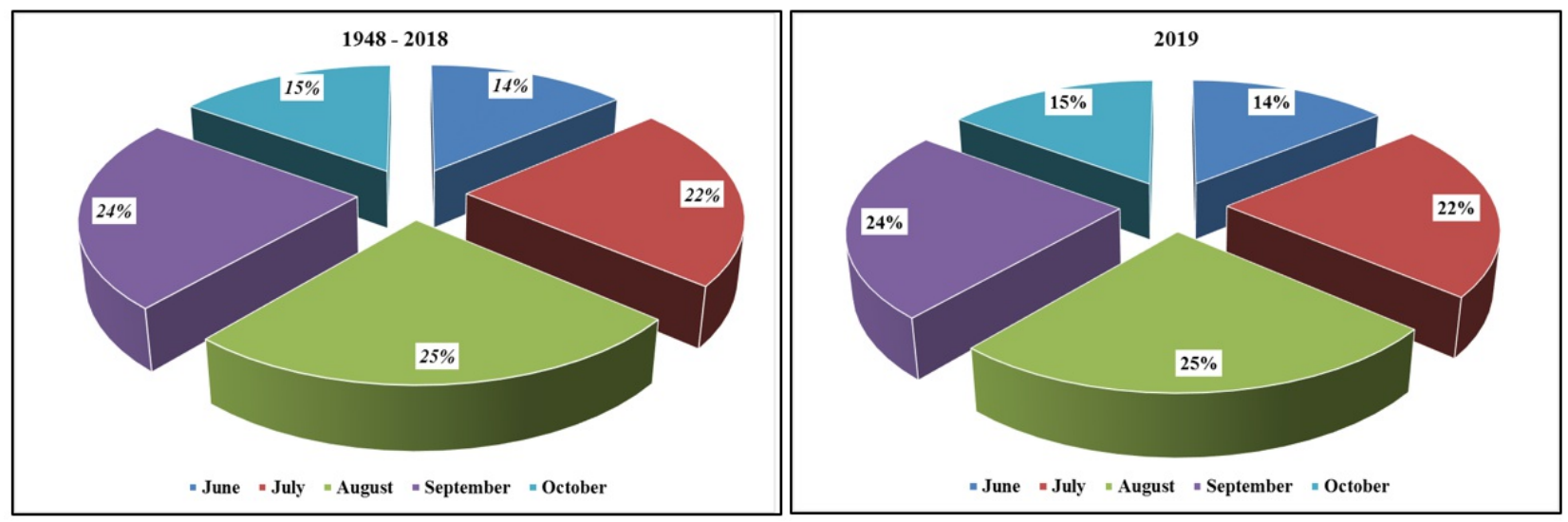

Figure 8

Percentages of monthly rainfall For June-October period
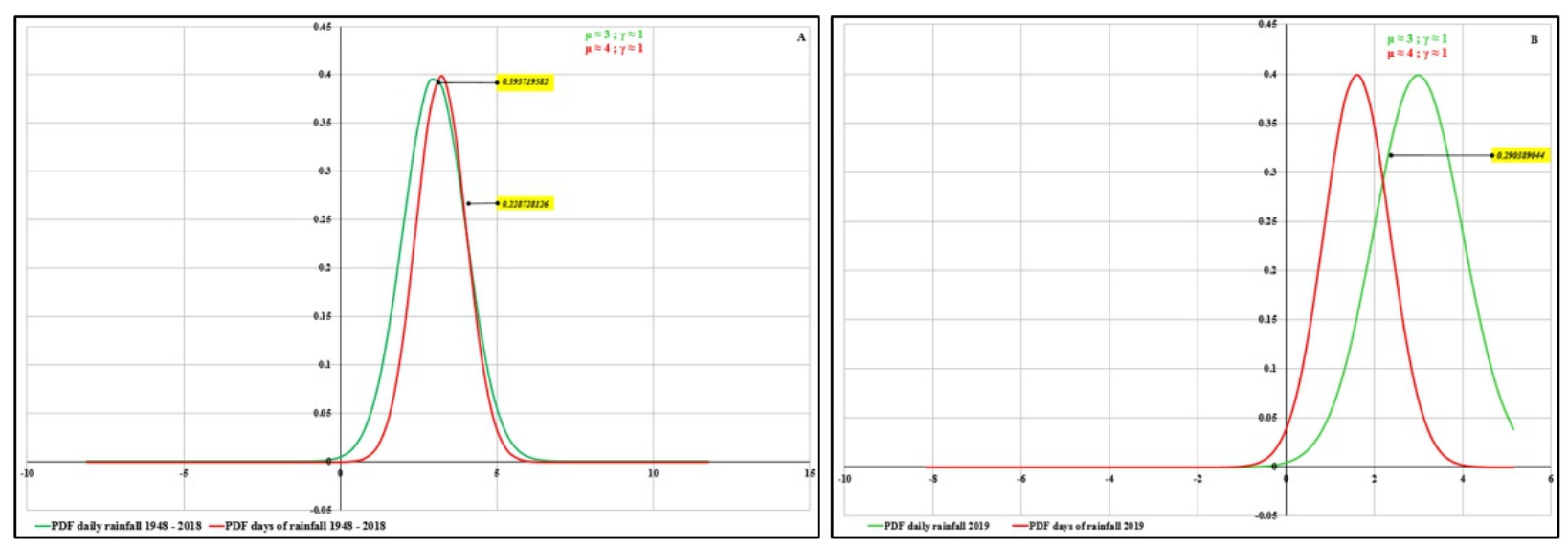

Figure 9

Individual PDF curves and their intersections before (A) and in (B) 2019
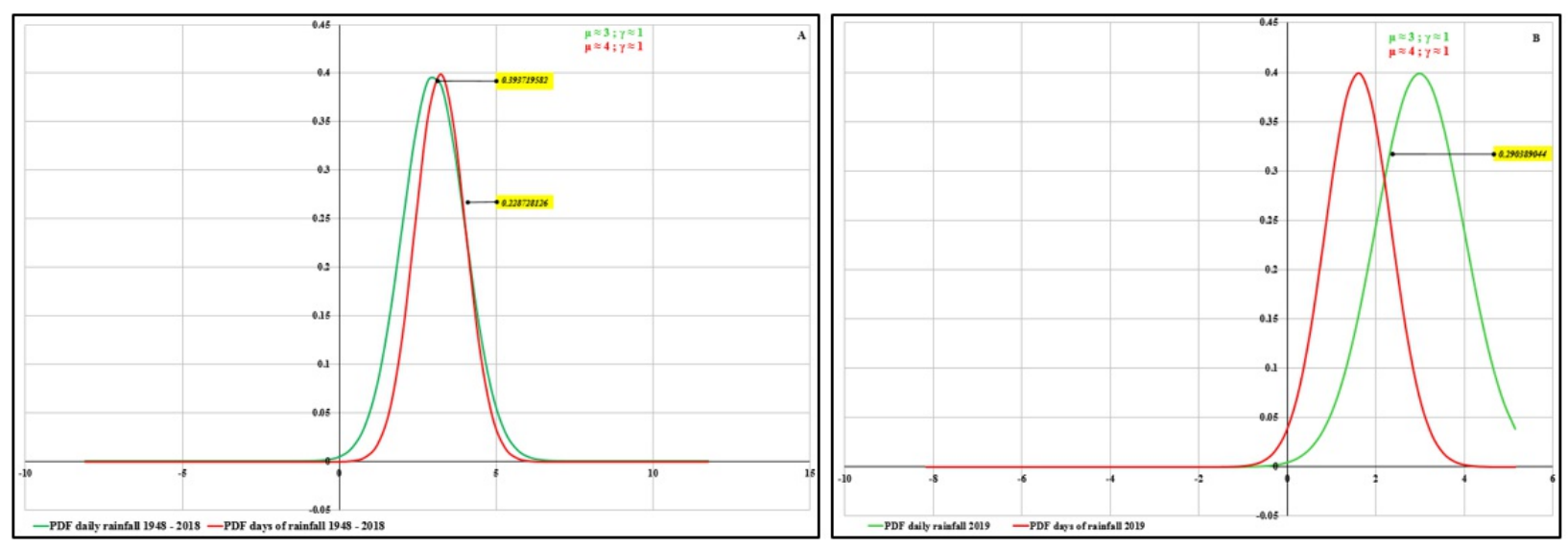

Figure 9

Individual PDF curves and their intersections before (A) and in (B) 2019 


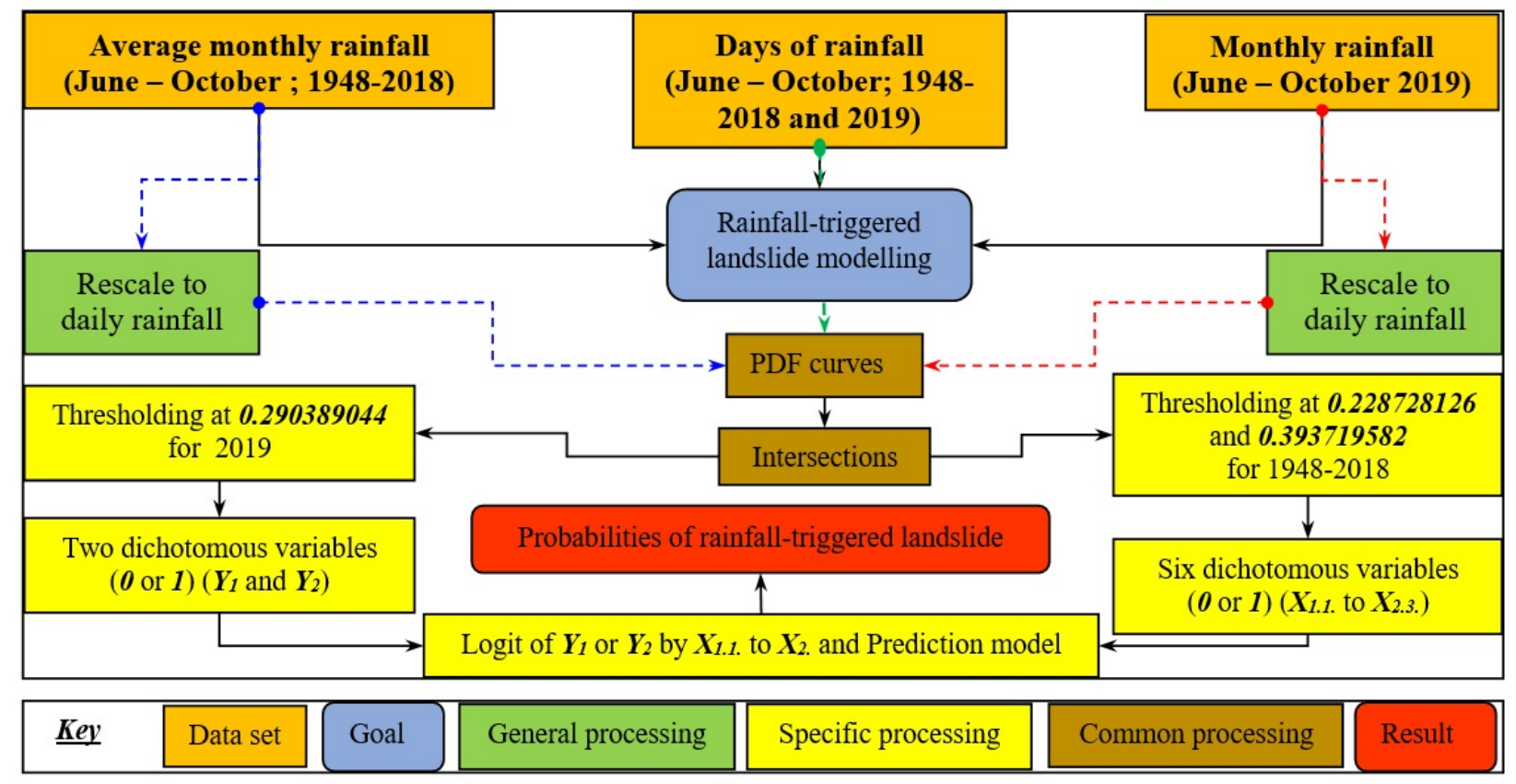

Figure 10

Workflow of the DRIP process

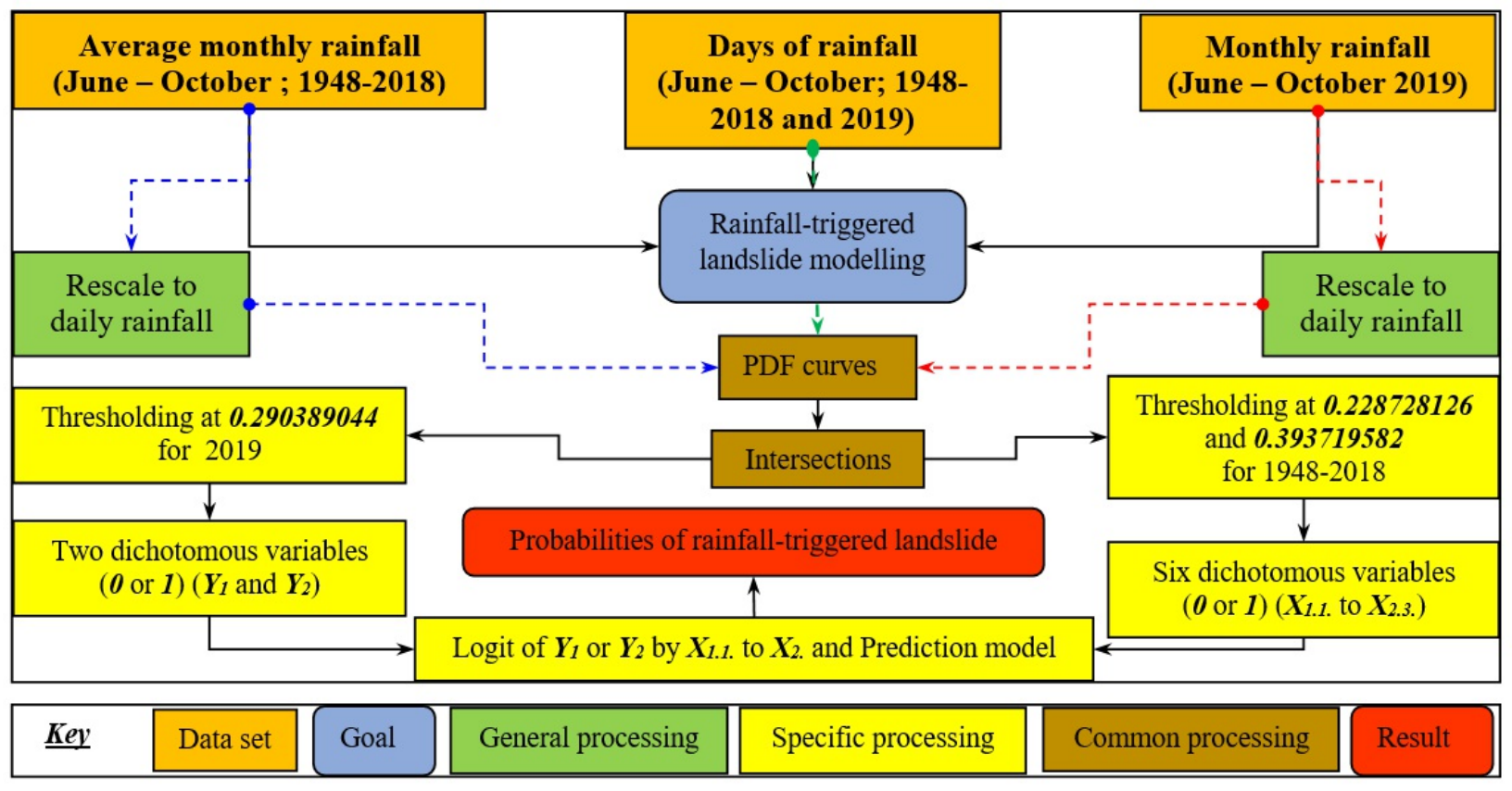

Figure 10

Workflow of the DRIP process 


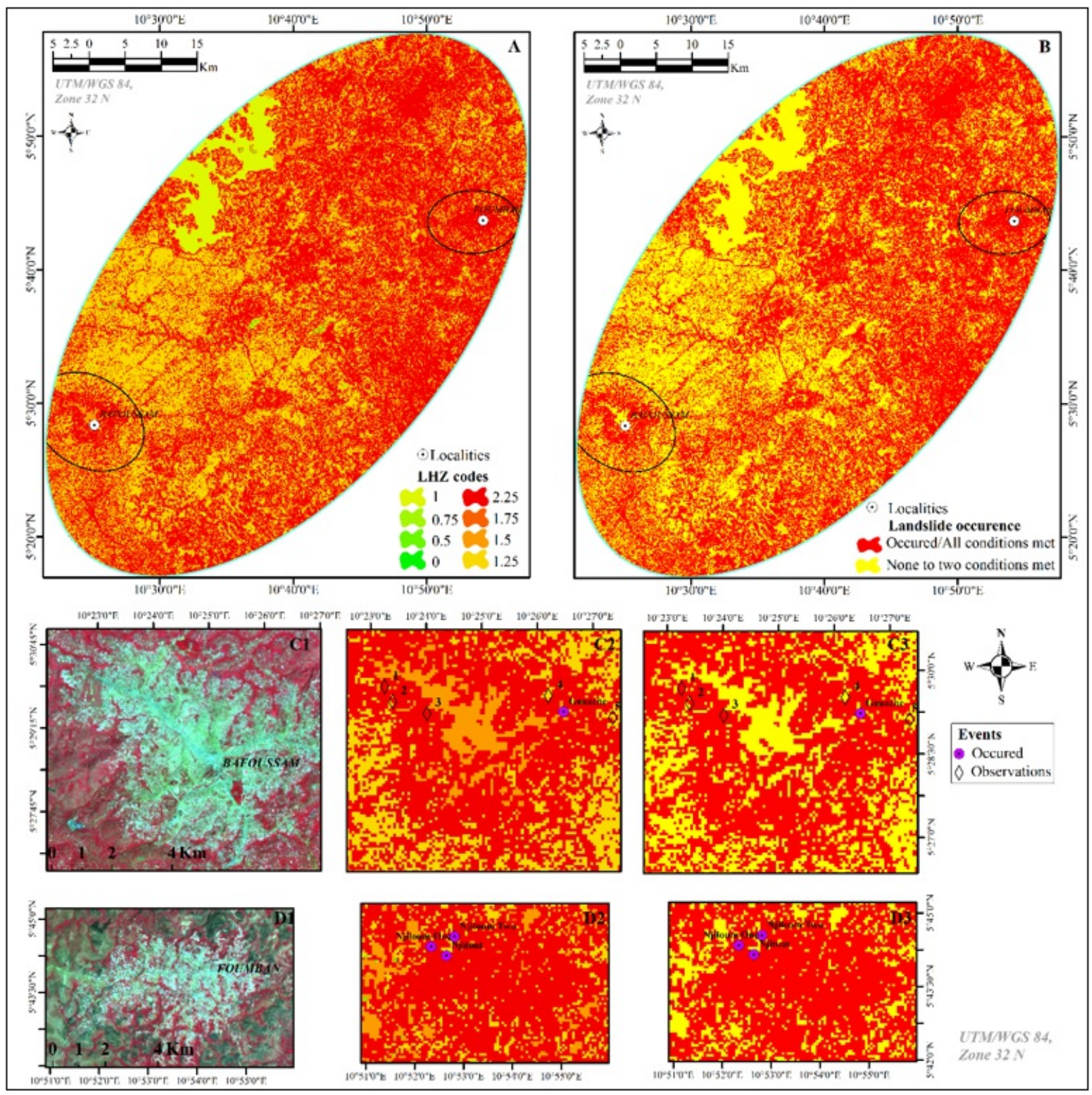

Figure 11

LHZ mapping. A) The eight classes and codes. B) Class 2.25 versus the other classes. C1) to C3) Patterns and accuracy assessment in Bafoussam. D1) to D3) Patterns and accuracy assessment in Foumban 


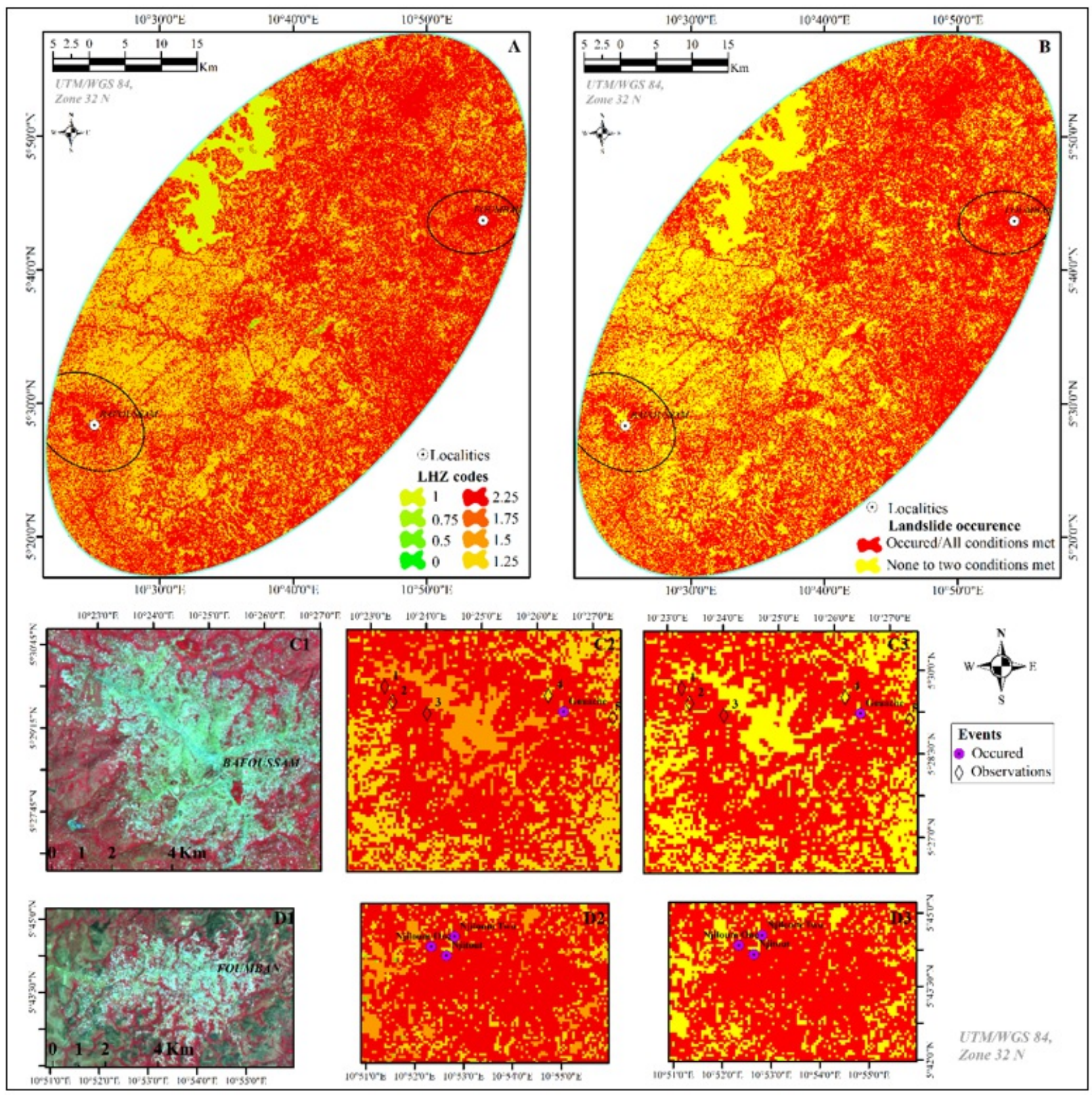

Figure 11

LHZ mapping. A) The eight classes and codes. B) Class 2.25 versus the other classes. C1) to C3) Patterns and accuracy assessment in Bafoussam. D1) to D3) Patterns and accuracy assessment in Foumban 


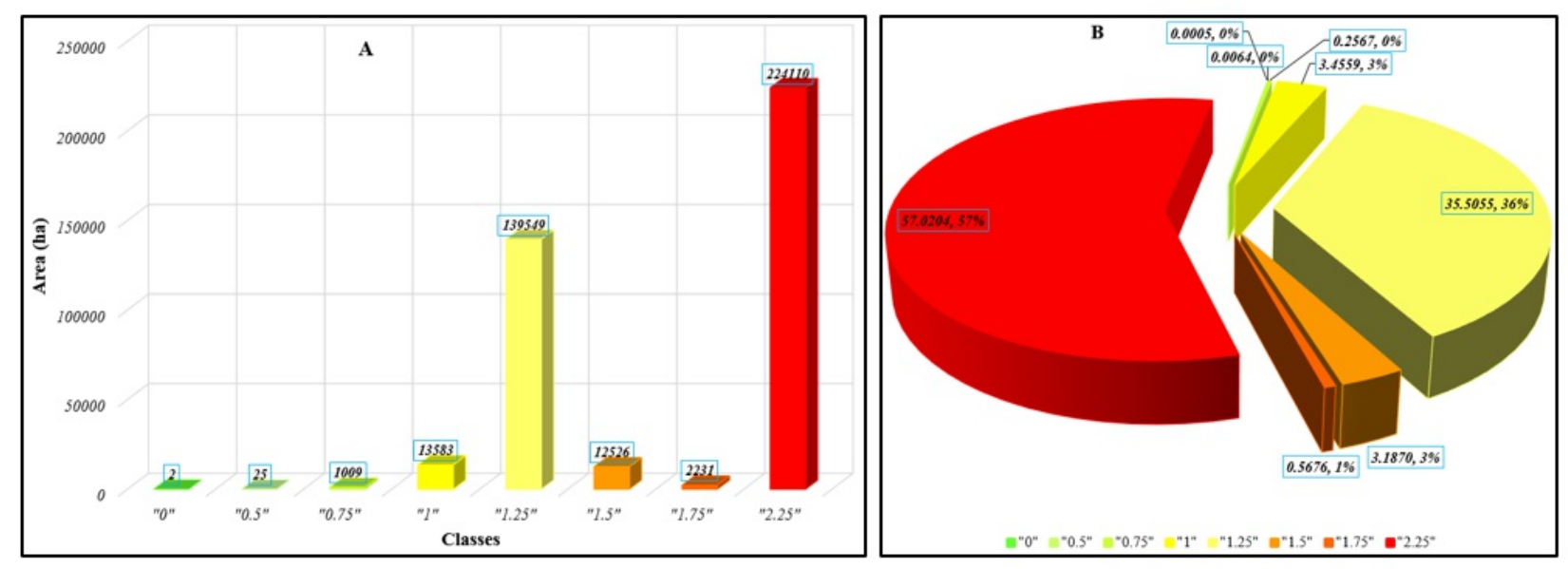

Figure 12

Areas (A) and percentages (B) of LHZ per classes

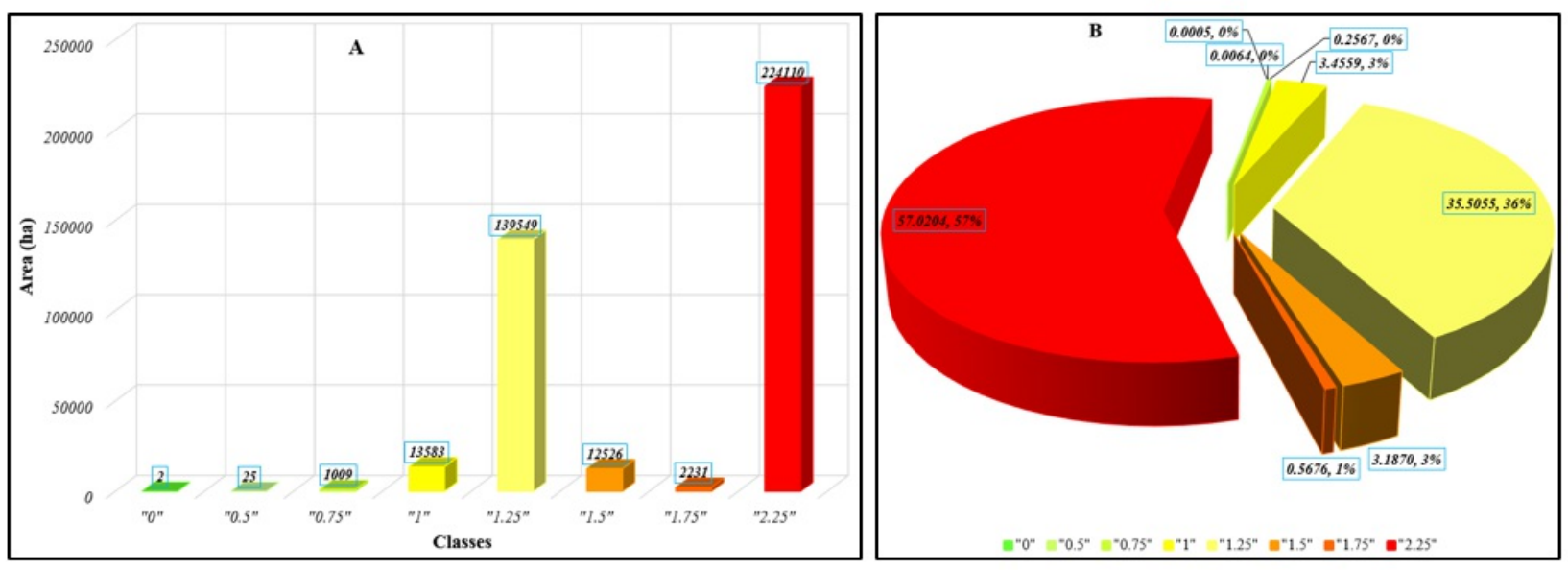

Figure 12

Areas (A) and percentages (B) of LHZ per classes 


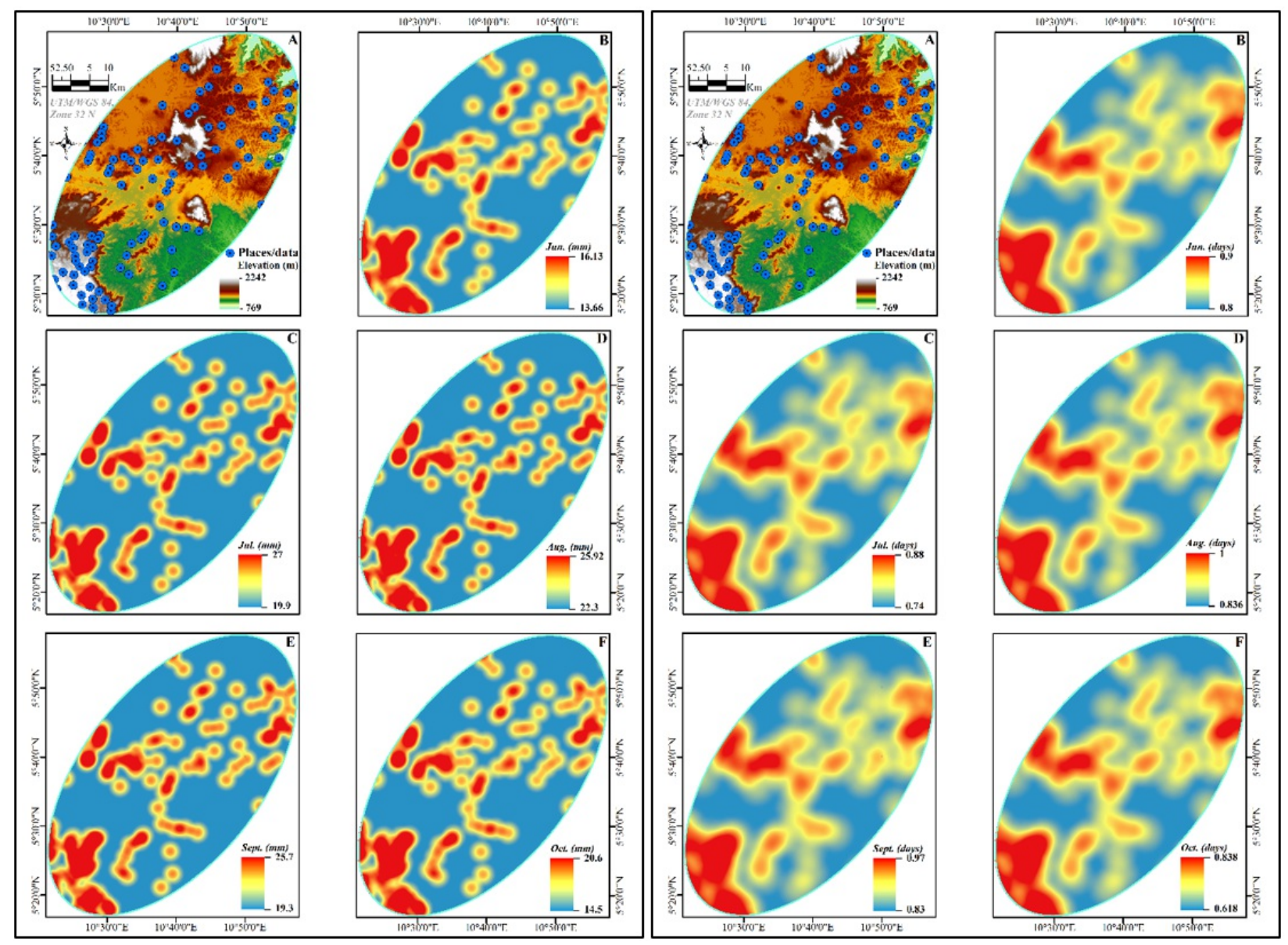

Figure 13

Daily rainfall (left) and days of rainfall (right) spatial distribution 


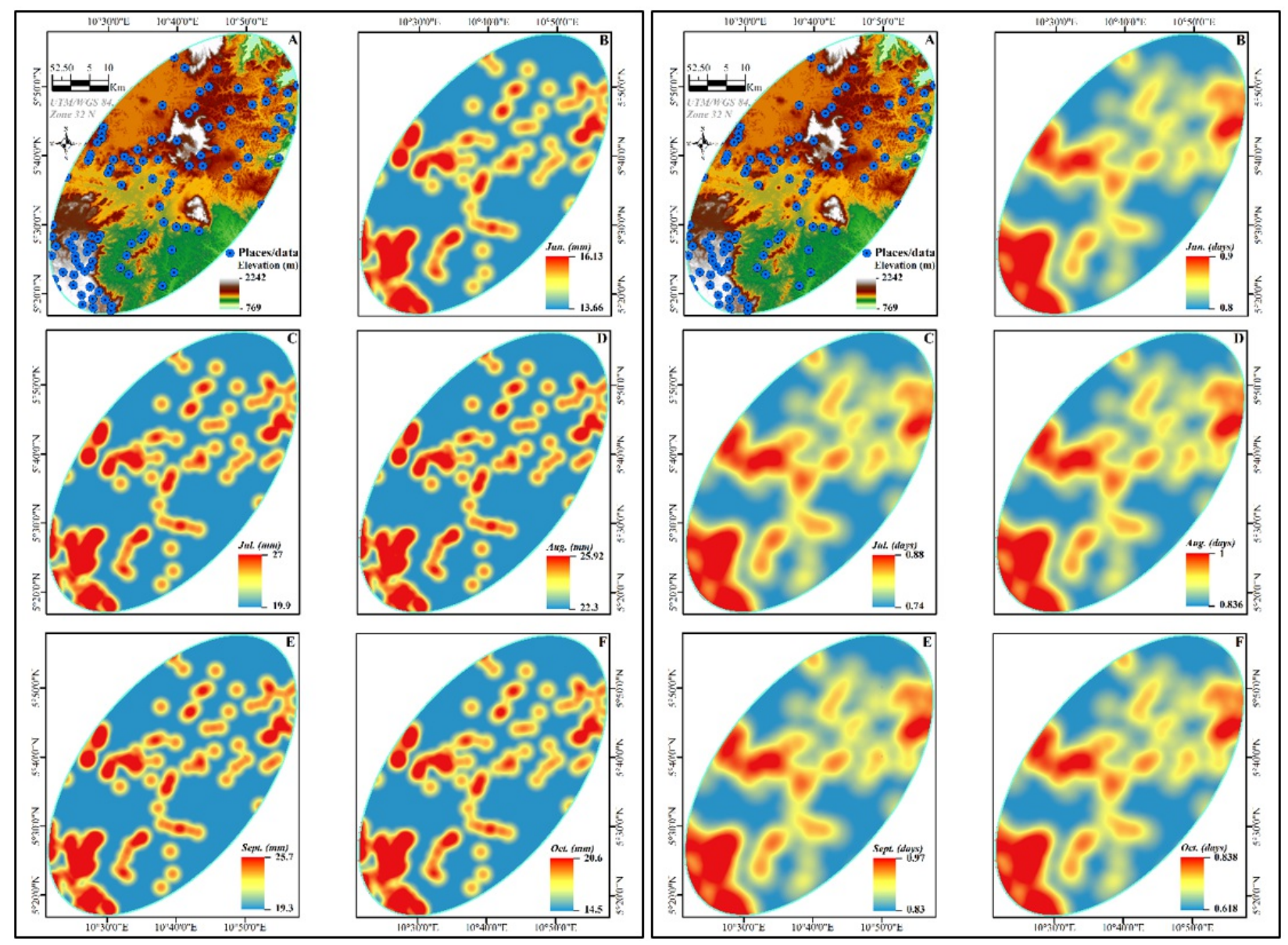

Figure 13

Daily rainfall (left) and days of rainfall (right) spatial distribution 


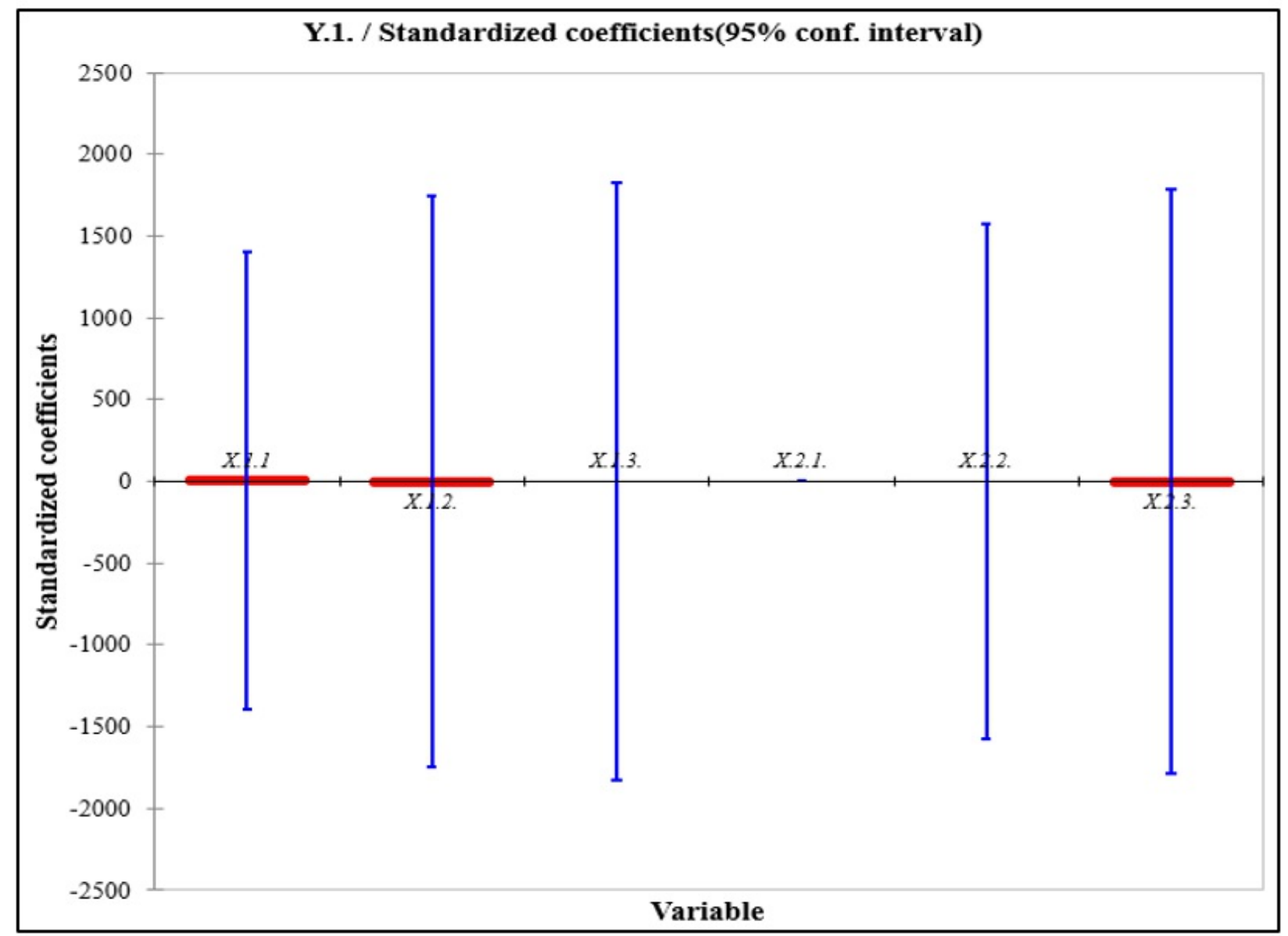

Figure 14

The standardized coefficients of the explanatory variables 


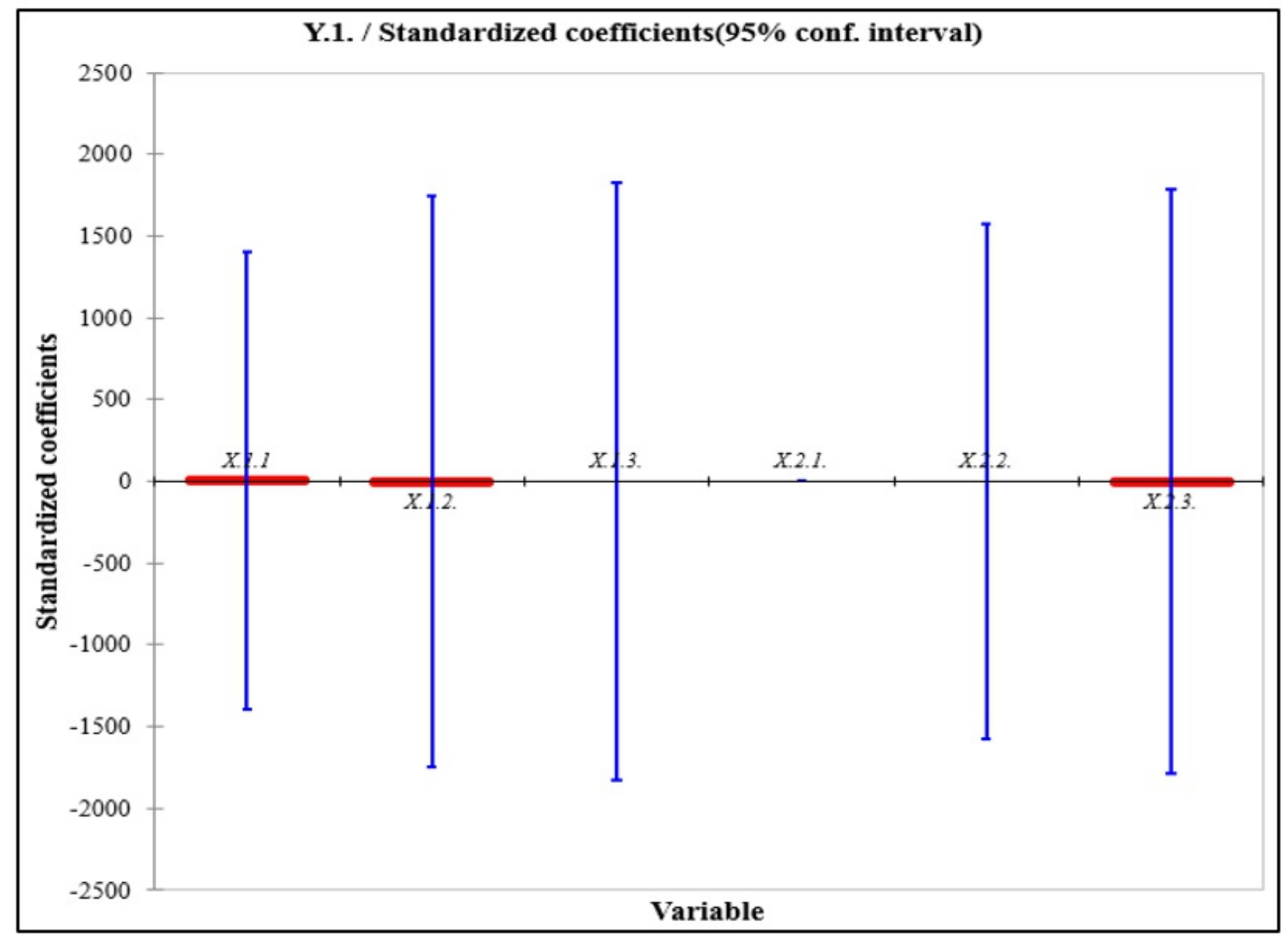

Figure 14

The standardized coefficients of the explanatory variables 


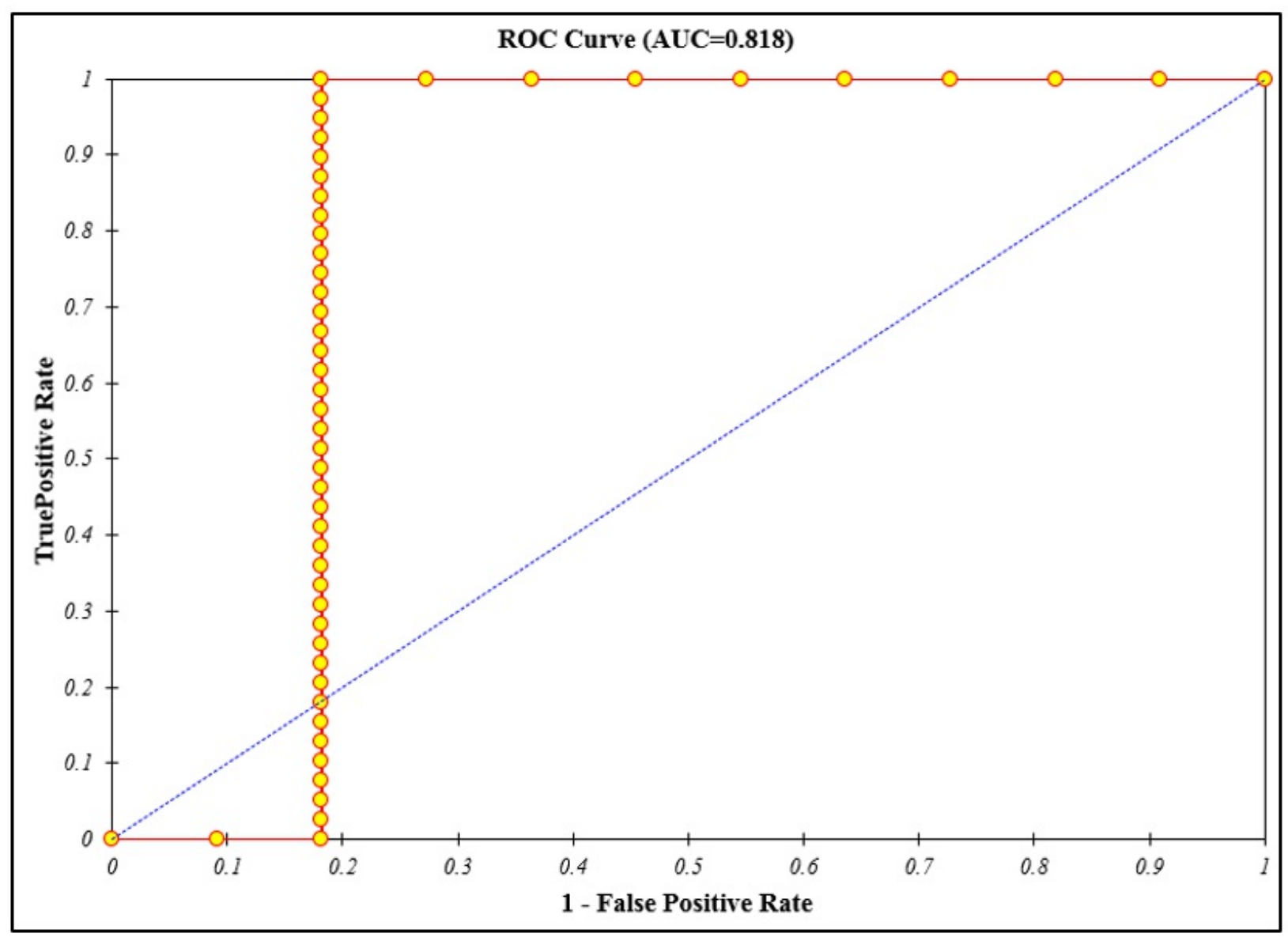

Figure 15

The Receiver Operating Curve of the model 


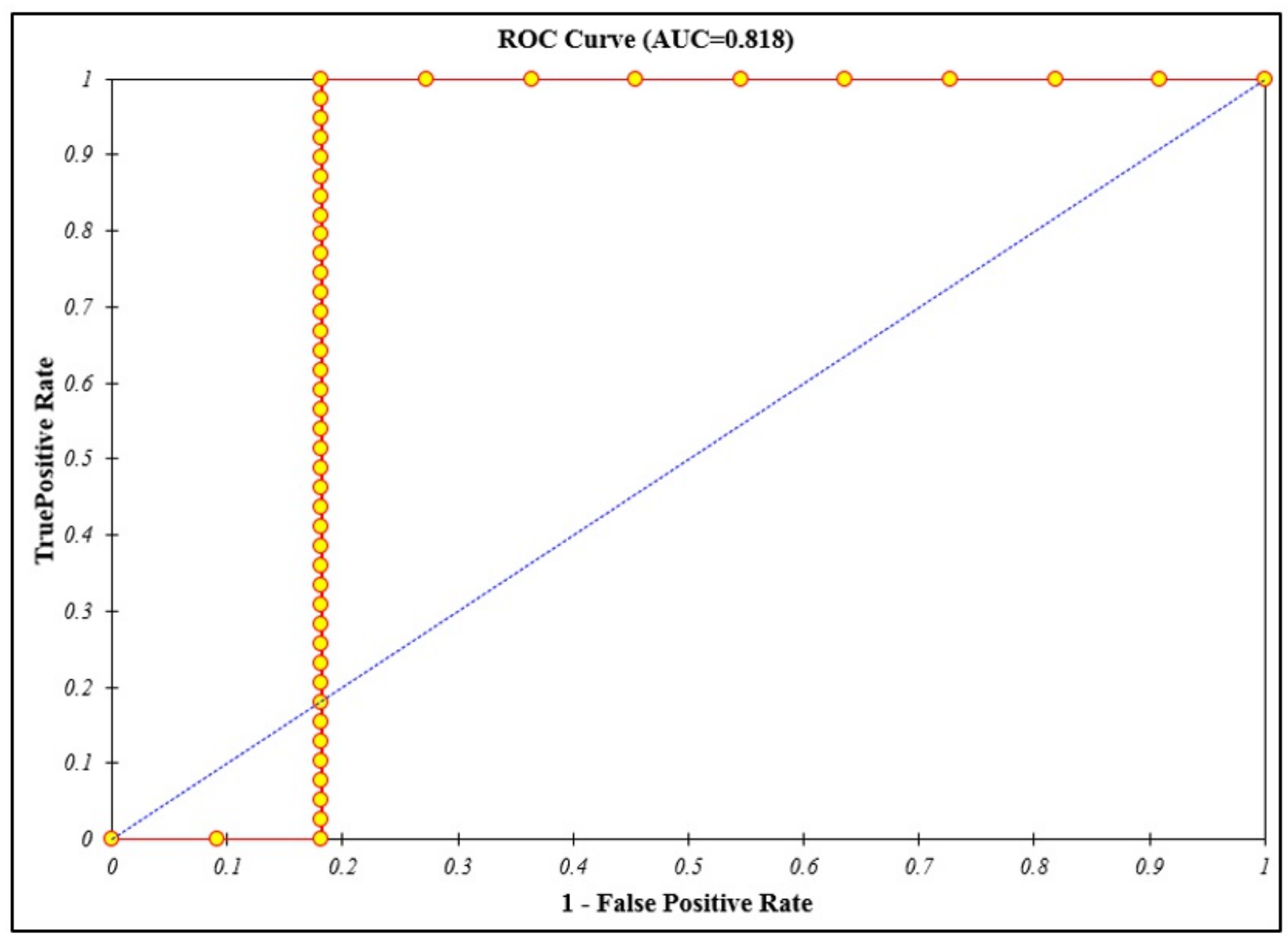

Figure 15

The Receiver Operating Curve of the model

\section{Supplementary Files}

This is a list of supplementary files associated with this preprint. Click to download.

Appendix.docx

Appendix.docx 